\title{
Hemifacial Microsomia
}

\author{
Anurag Jain, Resident, Neena Chaudhary, Pool Officer, Gul Motwani, \\ Senior Specialist, Atul Mittal, Senior Resident \\ Department of ENT, Safdarjang Hospital, New Delhi-110092
}

Congenital abnormalities of face emerge as a constellation of malformation of structures which arise from the first and the second branchial arch and the intervening first pharyngeal pouch and the primordia of the temporal bone. When fully expressed, a patient with hemifacial microsomia [Syn: otomandibular dysostosis] exhibits usually unilaterally under developed external or middle ear, mandible, zygoma, maxilla, temporal bone, facial muscles, muscles of masticiation. Many cases however, have been reported where the syndrom is not fully expressed (Grabb 1965).

\section{Key Words}

Hemifacial microsoma, Otomandibular dysostosis.

\section{CASE REPORT}

An 8 years old boy presented to us with left facial asymmetry and deformity of left pinna. Patient was born full term after a normal pregnancy and labour. His birth weight was normal and there was no history of any maternal illness, drugs or radiation during pregnancy. When first examined, there was hypoplasia of malar bone and mandible on the left side resulting in left facial asymmetry (Fig.1). This was associated with left facial paresis. Patient also had microtia on the left side with an accessory article in front of the tragus. Left external auditory canal was narrowed but intact tympanic membrane could be seen through it. Left mastoid process was also hypoplastic. Dental occlusal plane was not canted.

Right side of face was normal. There was no associated ocular deformity. On investigating the patient, $50 \mathrm{~dB}$ conductive hearing loss was observed on the left side. Tympanometry revealed a flat ' $B$ ' type of curve with absent acoustic reflex (Fig. 2). Facial nerve conduction study revealed that though the response was present on both sides, it was with delayed latency and low amplitude on the left side (Fig.3). Computereized axial tomography of the temporal bone showed an incompletely developed middle ear with a

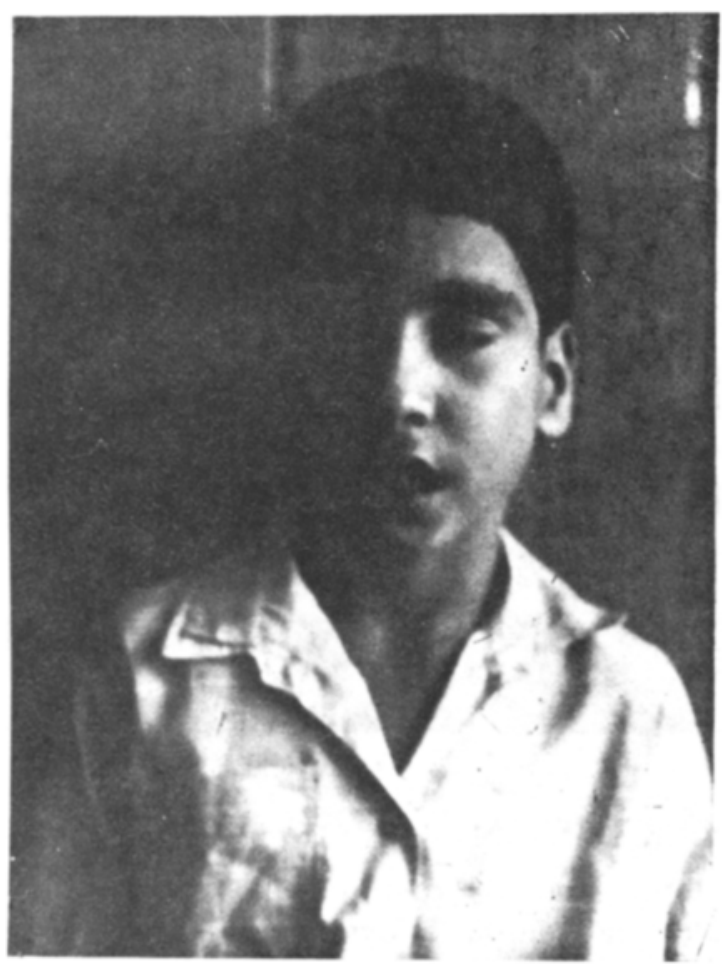

Fig-1

single rudimentary ossicle on left side. Mastoid process was hypoplastic with sclerosis of the air cells. Facial canal was clearly seen (Fig.4, 5). A 
patent sphenopetrosal cleft was seen on the left side. Right temporal bone appeared normal. Routine haematological investigations were normal. Radiographs of chest and vertebral spine,
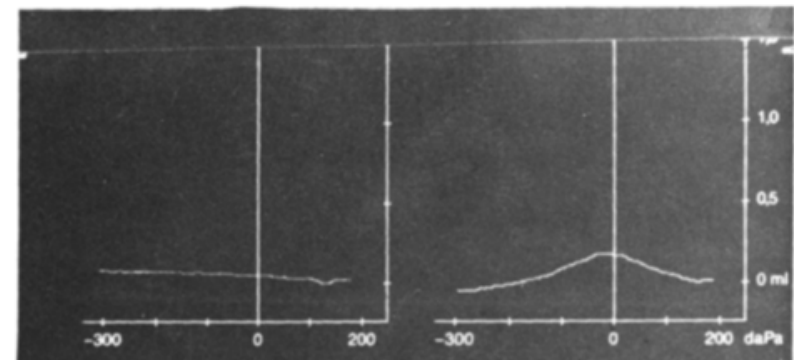

\section{Volume} $\mathrm{ml}$

Compliance

Pressure

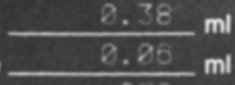

daPa

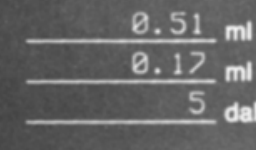

I

Fig-2

ultrasound abdomen were normal thus ruling out any abnormality in the kidneys, lungs and the spine.

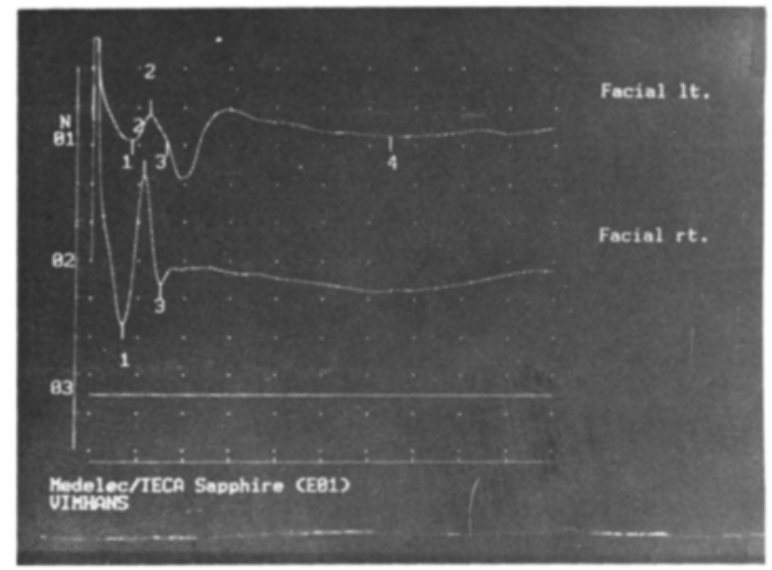

Fig-3

\section{DISCUSSION}

Hemifacial microsomia also known as otomandibulo facial dysostosis is a syndrome with variable and often wide spread involvement of ear, jaws and the adjacent skeletal and soft tissue structures resulting from maldevelopment of the frist and the second branchial arches (Converse 1973).
In a developing embryo, the first branchial arch gives rise to maxilla malar area, incus, malleus, mandible and muscles of mastication. The nerve is the madibular branch of trigeminal. The second arch forms of facial expression supplied by the racial nerve. The first branchial pouch grows laterally to form the eustachian tube and the

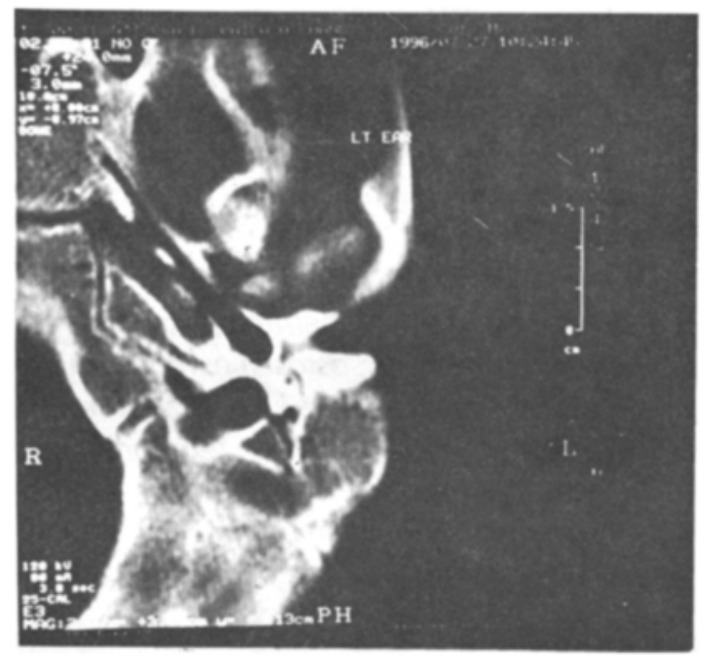

Fig-4

middle ear while the groove is deepened to form the external auditory canal. The pinna is formed from a number of tubercles which appear at the dorsal ends of the first and second branchial arches. These tubercles surround the dorsal end

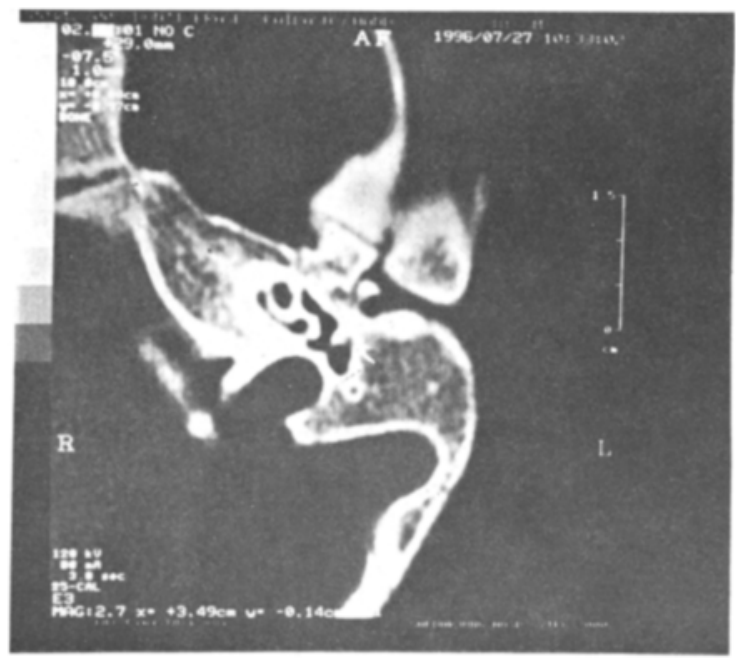

Fig-5 
of 1 st groove which is to form the external auditory meatus.

Poswillo (1974) demonstrated that destruction of differentiating tissues in the region of the developing ear and jaw by a teratogenically induced, expanding hematoma produced a branchial arch dysplasia. Thus craniofacial microsomia should probably be regarded as a non specific symptom complex the pathogenesis of which may have different aetiologies.

Its incidence is 1 in 5642 live births with equal ratio in males and females (Grabb). in $70 \%$ of the cases, hemifacial microsomia is unilateral and when it is bilateral, it is always bilaterally asymmetrical which is in contrast to the Treacher Collins syndrome which is always bilaterally symmetrical. Facial weakness, usually affecting the lower face occurs in $10 \%$ of the patients. Congenital heart diseases, pulmonary agenesis or hypoplasia and renal abnormalities including absent kindney, double ureter and anomalous blood supply may be associated with the syndrome. The ear abnormalities associated with the syndrome includes, microtia, accessory auricles and sinus tract. Conductive hearing loss due to middle ear abnormalities and/or and sinus tract. Conductive hearing loss due to middle ear abnormalities and/or absence or deficiency of the external auditory meatus is found in some $40 \%$ of patients. It variant oculoauriculovertebral dysplasia, also known as the Goldenhar syndrome is characterized by vertebral anamolies and epibulbar dermoids.

\section{SUMMARY}

We are reporting a rare case of typical hemifacial microsomia. The patient had unilateral hypoplasia of face, facial paresis, congenital malformation of auricle, external auditory canal as well as the middle ear.

\section{References}

1. Aduss Howard (1981): Form function growth and craniofacial surgery. OCNA Vo. 14: No.4, p 783-826.

2. Converse, J.M. et al (1973): The corrective treatment of the skeletal asymmetry in Hemifacial Microsomia. Plastic and Reconstructive Surgery 52 : $p$ 221-231.

3. Grabb, W.C. (1965): The first and second branchail arch syndrome. Plastic and Reconstructive Surgery $36: p 485-508$.

4. James, D.R. Craniofacial anomalies. Scott-Brown's V Ed. p.225-275.

5. Meurman, YRJO (1957) : Congenital Microtia and meatal atresia. Arch. of Otolaryngology 66 : p443-463.

6. Morcos, Nessim et al (1968): Goldenhar's syndrome, BMJ 1, p 489-490.

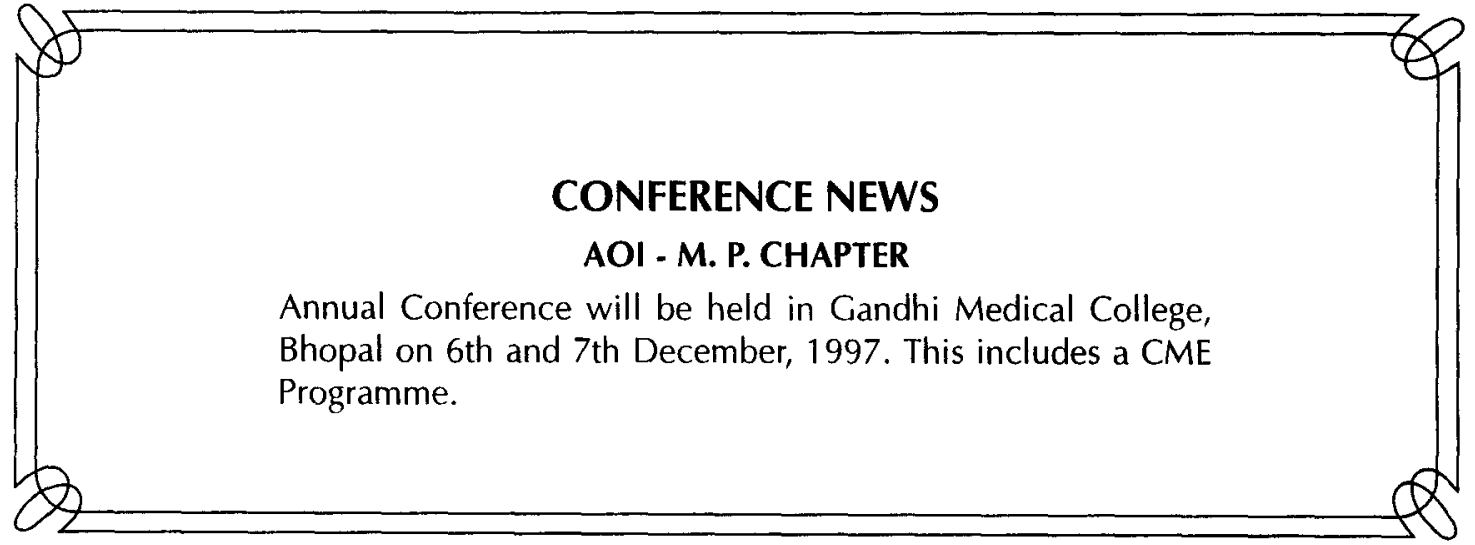

